\title{
EL RÉGIMEN SOCIETARIO DE LAS SOCIEDADES \\ LABORALES EN LA NUEVA LEY 44/2015, DE 14 DE OCTUBRE, DE SOCIEDADES LABORALES Y PARTICIPADAS
}

\author{
POR \\ Encarnación GARCÍA RUIZ ${ }^{1}$
}

\section{RESUMEN $^{2}$}

La ley 44/2015, de 14 de octubre, de sociedades laborales y participadas, pretende acomodar los diversos instrumentos, límites y exigencias con los que configura el régimen jurídico de las sociedades laborales, al actual contexto socio económico y legal donde éstas deben desenvolver su actividad económica. La finalidad propuesta por la ley es preservar su especial naturaleza jurídica, a la vez que persigue modernizar su estructura jurídica, sin debilitar el perfil social que se les demanda. La nueva ley recoge dos figuras organizativas, las sociedades laborales y, las que llama sociedades participadas, de esta última, solo deja constancia de qué hay que entender por ellas remitiendo su regulación a un futuro desarrollo reglamentario. En espera de ese anunciado Reglamento, nuestro trabajo se ha ceñido al aspecto societario de las sociedades laborales analizando las modificaciones realizadas en torno a los elementos tipológicos y de régimen jurídico de estas figuras organizativas para constatar si la vigente ley es el instrumento necesario y suficiente para alcanzar el reto propuesto.

Palabras clave: Economía social, Sociedad Laboral, Reforma legal, Elementos tipológicos y régimen jurídico.

Claves Econlit: K22, K23, K230.

\footnotetext{
${ }^{1}$ Profesora de Derecho Mercantil. Universidad de Almería. Dirección de correo electrónico: egruiz@ ual.es.

${ }^{2}$ Trabajo realizado en el marco del Proyecto de Investigación "Integración cooperativa y reestructuraciones responsables. Mecanismos de creación de empleo e incremento productivo empresarial" con referencia DER2013-48864-C2-1-P. Ministerio de Economía y Competitividad.

REVESCO No 123 - Primer Cuatrimestre 2017 - ISSN: 1885-8031 - www.ucm.es/info/revesco

http://dx.doi.org/10.5209/REVE.52991

Fecha de recepción: 06/03/2016

Fecha de aceptación: 17/06/2016
} 


\title{
THE CORPORATE REGIMEN OF LABOUR COMPANIES IN THE NEW ACT 44/2015, ON 14TH OCTOBER, OF LABOUR AND INVESTEE COMPANIES
}

\begin{abstract}
Act 44/2015, on 14th October, of labour and investee companies, aims to accommodate the different instruments, limits and requirements with which the legal regime of the labour companies is set, to the current economic and legal context where they must develop their economic activity. The purpose of the law is to preserve their special status, while it seeks to modernize its legal structure to ensure the economic solvency of the business plan, without weakening the social profile that is required. The new law includes two organisational figures, 'labour companies' and the calling 'investee companies', of the last one, only leaving evidence of what is to be understood by them referring its regulation to a subsequent regulatory development. Until the publication of the regulation, our work has focused on the corporate aspect of the labour companies by analysing the modifications made on the typological elements and legal regime of these organisational figures to determine whether the law is the necessary and sufficient instrument to achieve the challenge proposed.
\end{abstract}

Keywords: Social economy, labor society, legal reform, elements of the type and juridical regimen.

\section{JUSTIFICACIÓN DE LA REFORMA LEGAL}

La Ley 44/2015, de 14 de octubre, de Sociedades Laborales y Participadas, (en adelante LSLP), deroga la hasta ahora vigente Ley 4/1997, de 24 de marzo, de Sociedades Laborales (LSL) y, cuantas disposiciones de igual o inferior rango se opongan a lo previsto en ella (Disp. Derogatoria única de la LSLP). Dando así cumplimiento, entre otras, a lo dispuesto en la Disposición Adicional séptima de la Ley 5/2011, de 29 de marzo de Economía Social, que ordenaba al Gobierno la revisión y actualización de la ya derogada LSL.

La nueva regulación tiene como finalidad declarada, actualizar su régimen jurídico para adecuarlo al nuevo marco normativo y sistematizar sus normas de forma más acorde con lo establecido en la Ley de Sociedades de Capital (LSC) ${ }^{3}$ que, como norma general se aplica a estas figuras organizativas en todo aquello que no queda desplazado por la LSLP como

\footnotetext{
${ }^{3}$ Reguladas por el Real Decreto Legislativo 1/2010, de 2 de julio, por el que se aprueba el Texto Refundido de la Ley de Sociedades de Capital (LSC).
}

REVESCO No 123 - Primer Cuatrimestre 2017 - ISSN: 1885-8031 - www.ucm.es/info/revesco 
norma especial. La LSLP configura a estas sociedades de economía social, y por tanto, idóneas como fórmulas de participación de los trabajadores por cuenta ajena, tanto en la propiedad de los medios de producción y participación en los órganos de decisión, como en los resultados empresariales. Se sigue de esta forma la dirección señalada por las políticas europeas.

En definitiva, con la reforma se pretende, de una parte, reforzar el carácter empresarial de este tipo societario y, de otra, fortalecer la naturaleza, función y caracterización de la sociedad laboral como entidad de la economía social, poniendo en valor sus especificidades, según anuncia el propio Preámbulo en su apartado III de la Ley que comentamos. ${ }^{4}$

La nueva ley se estructura a lo largo de 3 capítulos. El primer capítulo mantiene el modelo social tipificado en la ley derogada con algunas modificaciones que son más coyunturales que estructurales, a las que nos referiremos seguidamente. El capítulo segundo consta de un único artículo dedicado al beneficio fiscal. Y el tercer capítulo, añadido en esta la Ley, recoge una nueva figura organizativa que llama "sociedades participadas", en el que solo se deja constancia de qué hay que entender por tal, posponiendo su regulación a un futuro desarrollo reglamentario (Disposición Final quinta "Habilitación para el desarrollo reglamentario”).

Nuestro objeto de estudio se ceñirá a los aspectos societarios de las sociedades laborales que hayan sido modificados por la nueva norma. Esta reforma legal ha sido muy demandada por los sectores económicos y jurídicos desde que se constata que, tal y como estaba configurado su régimen jurídico no alcanzaba a garantizar la finalidad propuesta por este tipo de sociedades, como es, que el control de la sociedad quede en manos de los socios

\footnotetext{
${ }^{4}$ Un estudio sobre el origen, evolución y papel socioeconómico que juega la figura que analizamos podemos verlo en PANIAGUA ZURERA, M. (2015) Las sociedades laborales en el Anteproyecto de Ley de Código Mercantil. En Estudios sobre el futuro Código Mercantil. Libro homenaje al profesor RAFAEL ILLESCAS ORTIZ. Universidad Carlos III de Madrid, pp.726 y ss. Del mismo autor (2015) La singularidad tipológica de la sociedad laboral y su legislación adecuada. (A propósito de la Proposición de Ley de sociedades laborales de Confesal y de la aplicación judicial de la Ley 4/1997, de sociedades laborales). Revista de Derecho de Sociedades, № 44 , pp. 171 y ss. También, en GARCÍA RUIZ, E. (2013) El régimen legal de las sociedades laborales sometidos a revisión. Revista de Derecho de Sociedades, No 41, pág. 249 y ss.; DE LUCAS Y CÁDENAS, J. (1996) Las sociedades anónimas laborales. En Comunidad de Bienes, Cooperativas y otras formas de empresas II, Madrid. Colegio Notarial de España, pp. 1.383 y ss. Hace un recorrido histórico por la normativa jurídica de estas sociedades; LEJARRIAGA PÉREZ DE LAS VACAS, G. Y MARTÍN LÓPEZ, S. (2013) La sociedad laboral: una forma de hacer empresa con historia. En LEJARRIAGA PÉREZ DE LAS VACAS, G, MARTÍN LÓPEZ, S.; MUÑOZ GARCÍA, A. 40 años de historia de las empresas de participación. Madrid: Escuela de Estudios Cooperativos, pp. 305 y ss.
} 
trabajadores por tiempo indefinido y que los trabajadores por tiempo indefinido no socios puedan alcanzar la condición de socio lo más fácilmente posible. ${ }^{5}$

Antes de entrar en el estudio de su vigente régimen jurídico, hay que recordar que la Sociedad Laboral es una sociedad de capital, con forma de anónima o de responsabilidad limitada, que una vez verificado administrativamente que cumple con los requisitos legales exigidos, obtiene la calificación de laboral para beneficiarse así de las ventajas fiscales que en ese caso se le reconocen. Por tanto, su complejidad jurídica radica en esa doble condición de sociedad de capital pero que organiza un proyecto empresarial que difiere del modelo puramente capitalista y que al ser calificada como «laboral» modifica su naturaleza jurídica pudiendo alcanzar la consideración de sociedad de economía social (García, 2013). Se trata, por tanto, de determinar si la nueva ley que regula a esta figura organizativa es el instrumento idóneo para alcanzar los fines propuestos por la misma, como es, modernizar su estructura jurídica, a la vez, que reforzar el perfil social que se le demanda. Para ello nos ocuparemos primero de la técnica legislativa utilizada en la norma, para después, entrar a analizar las modificaciones sustantivas de los elementos tipológicos de la figura analizada y de su régimen jurídico.

\section{LA TÉCNICA LEGISLATIVA SEGUIDA POR LA NUEVA NORMA}

El régimen jurídico de las sociedades laborales sigue sin contar con una regulación específica de las singularidades de este tipo de sociedades que permita transmitirle la seguridad jurídica de la que adolecen.

Según el propio legislador "las sociedades laborales son sociedades de capital por su forma y por tanto le son aplicables las normas relativas a las sociedades anónimas y limitadas" (Párrafo II de la Exposición de Motivos y artículo 1.1 LSLP). Es lógico pensar que las sociedades laborales quedan sometidas a la LSC, y que esta, solo quedaría desplazada en aquéllos aspectos que regula la LSLP como ley especial (Embid, 2015). No obstante, la redacción de la Disposición Final tercera, rubricada "Derecho supletorio" puede crear

\footnotetext{
${ }^{5}$ La reforma del Régimen Jurídico de las Sociedades Laborales fue impulsada por la Confederación Empresarial de Sociedades Laborales (CONFESAL) que encargó a un grupo de profesores universitarios (Fajardo García, G. / Alguacil Marí, P./López Gandía, J.) un documento base que fue sometido a estudio en un Simposio celebrado en Sevilla los días 30 y 31 de enero de 2008. De lo dicho allí, salió un texto integrado con la Ley 4/1997, con las reformas propuestas, dando lugar a la Proposición de Ley de las Sociedades Laborales, de fecha 3 de marzo de 2009. Sobre el que tuvimos ocasión de reflexionar en GARCÍA RUIZ, E.(2013) El Régimen legal de las sociedades laborales sometido a revisión op. cit. El contenido de la Proposición fue modificado posteriormente y dado a conocer por CONFESAL bajo la denominación de Propuesta de Ley de Sociedades Laborales en febrero de 2013 .
}

REVESCO No 123 - Primer Cuatrimestre 2017 - ISSN: 1885-8031 - www.ucm.es/info/revesco 
confusión y entenderse que cambia el criterio cuando establece que "En lo no previsto en esta ley, serán de aplicación a las sociedades laborales las normas correspondientes a las sociedades anónimas o de responsabilidad limitada, según la forma que ostente."

La conclusión a la que llegamos es que la técnica seguida en la LSLP no ha sido mejorada. La nueva ley mantiene la técnica de remisión general al régimen jurídico de la forma que adopte, anónima o de responsabilidad limitada, como hacía su predecesora, al igual que mantiene la parquedad de su contenido legal, despachando su régimen jurídico societario en apenas 17 artículos. Sí, se observa, que el contenido de esos preceptos es menos imperativo introduciendo la norma un mayor margen a la autonomía de la voluntad de los socios en la configuración de su régimen jurídico.

Esta técnica legislativa ya fue criticada en su día por la doctrina ante las dificultades prácticas que presentaba una remisión generalizada a la LSC, debido a que en muchas ocasiones se produce una importante inseguridad jurídica, al no poderse transponer la norma directamente ni encontrar respuesta en el régimen especial previsto en su ley específica dada la parquedad de la misma (así, entre otros, Fajardo 2008; Cano, 1997 y 2008). No parece verlo así el legislador, ya que en el Preámbulo de la LSLP, párrafo I, establece "que la distinción principal entre las sociedades de capital no es tanto por su forma como por su condición o no de sociedad cotizada." Por lo que entendemos que considera que no debe haber problemas en la acomodación entre el régimen general previsto en la LSC y el régimen especial previsto en la LSLP a pesar de que ambos tipos tienen una naturaleza jurídica bien distinta.

En cualquier caso, esta técnica legislativa no garantizó en su momento una gestión societaria motivada por el “intuitu personae," verdadero elemento cimentador de este tipo societario.

Esta indefinición legal refleja la falta de consenso científico acerca del sentido institucional de esta figura organizativa, dividida entre los que la consideran una simple sociedad mercantil de capital especial (Portellano y Mercader 1997 o Uría, Menéndez y Vérgez 2006) y los que ven en ella una estructura organizativa de base mutualista, que en definitiva es lo que articula la causa del contrato de estas sociedades, por cuanto, el fin común se cumple con la participación directa de los socios en el desarrollo del objeto social propuesto (Vargas, 2006 o Paniagua, 2005). 
En este contexto legal serán los socios vía estatutos sociales los que doten a su organización societaria de un cariz, más social o más capitalista según les interese, en aquéllos aspectos no regulados específicamente por la LSLP.

Por tanto, desde la perspectiva de la técnica legislativa la reforma solo alcanza a conseguir una redacción más clara y una mejor reubicación de algunos de sus contenidos que hace a esta ley más eficiente, por lo demás, sigue creando confusión sobre la naturaleza jurídica de este tipo de sociedades.

\section{MODIFICACIONES APRECIADAS EN LOS ELEMENTOS TIPOLÓGICOS Y DE RÉGIMEN JURÍDICO DE LAS SOCIEDADES LABORALES}

Según la propia Exposición de Motivos de la LSLP, se ha mejorado el régimen jurídico de las Sociedades Laborales ya que son de capital por la forma, pero de naturaleza social por sus fines y principios orientadores, al estar participadas por los socios trabajadores y abiertas a la integración de los demás trabajadores de la empresa. Y, a fin de preservar su singular naturaleza jurídica introduce mejoras en esas dos direcciones, de un lado, pretende fortalecer su vertiente empresarial y consolidar el carácter estable y no coyuntural de este modelo empresarial, además de preparar su contenido a los cambios que se producirán en torno al documento único electrónico. De otra parte, persigue facilitar el acceso a la condición de socio e incorpora medidas para asegurar el control de la sociedad por parte de los trabajadores y, aumentar la utilidad y preferencia de las sociedades laborales por parte de los emprendedores.

Para conocer si efectivamente se ha mejorado el régimen jurídico de estas sociedades, tal y como afirma la exposición de motivos de la ley, seguiremos el curso natural sobre el que transita la especial naturaleza de estas sociedades, que viene determinada por los elementos tipológicos que la configuran, a los que hay que añadir los requisitos legales exigidos para obtener la calificación de «laboral », calificación que solo pueden obtener, tras un procedimiento administrativo previsto en la LSLP. 


\subsection{Los elementos tipológicos que configuran a las Sociedades Laborales}

Con mejor redacción que su predecesor, el artículo 1 de la LSLP sigue conteniendo los elementos conceptuales o tipológicos de esta figura y, ahora también, recoge algunos de los requisitos exigidos por la ley para obtener la calificación de laboral, antes dispersos por el texto legal derogado. En la base de estas sociedades sigue estando como piedra angular la doble condición de socios y trabajadores por tiempo indefinido que prestan para la sociedad servicios retribuidos en forma personal y directa, donde el capital debe estar proporcionalmente repartido entre todos $\mathrm{y}$, donde se le da prioridad a que los trabajadores por tiempo indefinido no socios puedan adquirir fácilmente esa condición (Batlle, 1996).

Por tanto, no se altera la naturaleza propia de este tipo de sociedades que sigue residiendo en torno al control que deben ejercer sobre la sociedad los socios trabajadores por tiempo indefinido, así como, en el principio democrático que requiere que los trabajadores con contrato indefinido puedan adquirir fácilmente la condición de socio.

En cuanto al control que los socios trabajadores deben ejercer sobre la sociedad, sigue siendo mediante el capital social [art. 1.2,a) LSLP]. Ello a pesar de la motivada reivindicación realizada en su día por la doctrina para cambiar el criterio y, seguir el del número de votos, dado que, sobre todo, en las sociedades de responsabilidad limitada la mayoría del capital no garantiza, siempre y en todo caso, el control de la sociedad (Olavarría, 2008 o Andreu, 2010). Ahora, con la intención de paliar la posible disfunción que puede darse entre el control de la sociedad y la propiedad del capital, se introducen excepciones al régimen general de acciones y participaciones sociales, exigiendo la LSLP que estas sean de igual valor nominal y confieran los mismos derechos. Como tendremos ocasión de ver en el epígrafe dedicado al régimen jurídico de estas sociedades.

Sí nos llama la atención de este apartado a) del punto 2 del artículo 1 que recoge el primer elemento morfológico de estas sociedades, que inicie su redacción con la expresión "Que al menos....", lo que parece dar a entender que, ahora, la mayoría del capital es el mínimo del que partir y no el máximo conformista como podía entenderse con la redacción del ex artículo 1 de la ley derogada. Seguramente en la mente del legislador está la necesidad de preservar el carácter social de estas sociedades, alentando así a la sociedad a seguir trabajando en pos de aumentar el porcentaje de capital en manos de los trabajadores no socios, como es deseable y parece ser el trasfondo de una parte de la reforma. 
En cuanto al referenciado principio democrático, se mantiene la obligación de proporcionalidad en el reparto del capital social entre todos los socios [art. 1.2,b) LSLP], mediante el cual se fortalece el carácter social de este tipo de sociedades. Así como, la prioridad a que los trabajadores por tiempo indefinido que no sean socios puedan adquirir fácilmente esa condición (Cavas y Selma, 2011). Por lo tanto, ambas exigencias de, mayoría del capital en manos de socios trabajadores por tiempo indefinido y de, un amplio reparto del capital social que exige imponer límites porcentuales en la tenencia del mismo, configuran los elementos tipológicos de control y amplia base democrática que permite clasificar a las sociedades laborales como una categoría especial de sociedades.

\subsection{Los requisitos legales exigidos para obtener la sociedad la calificación de «laboral»}

A los elementos definitorios o configuradores del tipo expuestos, se le anudan los requisitos exigidos por la ley para que una sociedad anónima o limitada pueda obtener la calificación de «laboral». Esos requisitos se concretan principalmente: en la imposición de límites al porcentaje de capital que cada socio trabajador o no, puede tener en la sociedad [art. 1.2,b) LSLP]; en la imposición de límites al número de horas trabajadas al año por trabajadores no socios [art. 1.2,c) LSLP], y por último, en la necesidad de una reserva especial (art. 14 LSLP). El incumplimiento de alguno de estos requisitos sigue siendo causa legal de que la sociedad pierda la calificación de «laboral» (art. 15 LSLP).

El primer requisito mencionado se concreta en lo dispuesto en el artículo 1,2,b) LSLP y ninguno de los socios podrá ser titular de acciones o participaciones sociales que representen más de la tercera parte del capital social. No obstante, Esta mayoría queda matizada por dos excepciones. Una, las sociedades laborales pueden constituirse con dos socios. Otra, introduce una ampliación de las organizaciones públicas y privadas a las que se les permite obtener un mayor porcentaje de capital social sin llegar al cincuenta por ciento.

Esta primera excepción es de nuevo cuño y no estaba prevista por la ley derogada. Ahora, con la vigente ley, dos socios trabajadores con contrato indefinido, siempre que se repartan el capital y los derechos de voto al cincuenta por ciento, pueden constituir una sociedad laboral. Con la obligación de que en el plazo máximo de 36 meses se ajusten al límite establecido con carácter general para estas sociedades [art. 1,2,b) II párr.].

Por tanto, esta posibilidad excepciona temporalmente la regla general del reparto proporcional del capital social entre socios trabajadores por tiempo indefinido. Ni el texto 
legal ni la exposición de motivos hacen referencia a por qué esta permisibilidad. ${ }^{6}$ Es posible que en la base de la misma esté dar facilidades para la elección de este tipo social si puede dar cobertura jurídica a pequeñas empresas que no necesiten más trabajadores para iniciar la actividad. Aunque con la cautela de que esta situación excepcional dure un tiempo limitado, entendemos que con el objeto de que no se caiga en la corruptela de que los demás trabajadores sean contratados a tiempo parcial, lo que iría en contra de la propia naturaleza de las sociedades laborales. Ahora bien, ¿que ocurre cuando transcurrido el plazo legal, la actividad empresarial no requiere más mano de obra porque no hay necesidad de más contrataciones? La sociedad laboral entraría en causa de descalificación o, estaría obligada sin necesidad a contratar por tiempo indefinido para mantener la calificación de «laboral».

La segunda excepción es más bien una matización de lo ya previsto en la ley derogada. Ahora, la LSLP amplía el número de posibles socios inversores, y además, se refiere a ellos por categorías amplias sin circunscribirse a entes públicos o privados específicos como antes. Así recoge como socios inversores a entidades públicas, de participación mayoritariamente pública, entidades no lucrativas o de la economía social. Los cuales pueden ser titular de un porcentaje de capital social superior a la tercera parte e inferior al cincuenta por ciento [art. 1.2,b) III párr.]. Entendemos que con el ánimo de que con ese incentivo decidan invertir en estas sociedades y éstas puedan acrecentar sus recursos económicos con los que afrontar con mayor seguridad los distintos ciclos económicos en un entorno competitivo y globalizador en el que tienen que desarrollar su actividad empresarial (García, 2013:25 o, Cano, 2002 o, Olavarría, 2008).

En caso de que se transgredan los limites antes expuestos concernientes a la conformación de la mayoría del capital en posesión de los socios trabajadores por tiempo indefinido o, alguno de estos socios supere el porcentaje de la tercera parte del capital social que como máximo pueden tener (art. 1.2 a y b LSLP), la sanción es la pérdida de la calificación de «laboral». ${ }^{7}$ No obstante, la sanción no es automática, la nueva norma admite la posibilidad de que la sociedad vuelva a acomodar la situación de los socios a lo dispuesto en la ley, para ello da un plazo de dieciocho meses desde que se originó el primer incumplimiento.

\footnotetext{
${ }^{6}$ El propio Consejo Económico y Social en Dictamen 6 2015, de 13 de Mayo sobre el Proyecto de esta ley, en su apartado cuatro, muestra su extrañeza ante esta excepción sin entender los motivos que la fundamentan.

${ }^{7}$ En la derogada Ley de Sociedades Laborales, para llegar a esta conclusión había que poner en relación el artículo 1 con el 16 que contenía las causas de la pérdida de laboral. Además el plazo para acomodar de nuevo la sociedad a la ley era de 36 meses, en la nueva ley hay una drástica reducción.
} 
La reducción de los plazos es una constante en toda la norma, ni en este caso, ni en los siguientes que hemos de ver, ofrece la norma razón alguna. Puede deberse al deseo del legislador de que la sociedad vuelva en el menor tiempo posible a cumplir con los requisitos exigibles para seguir manteniendo la calificación de «laboral», sin dar opción a que la sociedad se acomode a una situación que debe ser excepcional si quiere seguir beneficiándose de las ventajas fiscales y sociales que otorga este tipo de sociedades.

El segundo requisito exigido por la LSLP para la obtención por la sociedad de la calificación de «laboral», es el control en el número de horas año trabajadas por los trabajadores contratados por tiempo indefinido que no son socios [art. 1.2,c) LSLP]. Este requisito obedece a la necesidad de que una sociedad de economía social, como es la laboral, no ceje en el empeño continuo de que el mayor número posible de trabajadores por tiempo indefinido sean, cuanto antes, propietarios de los medios de producción. Este requisito exigido también por la LSL derogada, ha sido quizás el más polémico entre la doctrina y el que se ha visto más modificado por la reforma. La polémica surgió porque la práctica había demostrado que, en muchas ocasiones, por razones ajenas a la voluntad de la sociedad no era fácil cumplir con lo ex preceptuado, más gravoso que en su redacción actual. Puesto que hay que conjugar en tiempo y forma, que haya títulos disponibles para adquirir y, trabajadores por tiempo indefinido no socios con voluntad y posibilidades económicas para adquirir dichos títulos en la cantidad suficiente y en el momento preciso para cumplir con esta exigencia. Lo que no siempre ocurre. La consecuencia ha sido que muchas sociedades se han visto abocadas a mantener en precariedad a más trabajadores de los deseados para no incurrir en el supuesto de hecho de la descalificación. Llegándose a pedir por un sector de la doctrina que desapareciera dicho requisito para obtener la calificación de laboral, ${ }^{8}$ mientras que otra importante corriente doctrinal, aun reconociendo los inconvenientes que conllevaba su cumplimiento tal y como estaba redactado en la norma derogada, mantenía que su eliminación erosionaría la propia idiosincrasia de la figura, ya que, permitiría otorgar la calificación de «laboral» a sociedades anónimas o limitadas donde una amplia parte de sus trabajadores no son propietarios de la empresa, que es lo que les permite poder pertenecer al grupo de sociedades de economía social. Aconsejándose buscar otras alternativas (Olavarría, 2008 o Cano, 2008).

\footnotetext{
${ }^{8}$ Propuesta recogida en el documento sobre la PLSL, realizado a instancias de CONFESAL, op.cit.
} 
Esta segunda opción ha sido la seguida por el legislador que no ha eliminado este requisito pero sí lo ha sometido a una importante modificación en la forma y en el fondo.

En la forma está redactado de modo menos farragoso y sencillo, y en el fondo, admite un aumento importante del volumen de horas año trabajados por los trabajadores por tiempo indefinido no socios que pasa del 15 por ciento en la norma derogada, al 49 por ciento del cómputo global, en la vigente ley, independientemente del tamaño de la sociedad «laboral». Para ese cómputo no se tiene en cuenta a los trabajadores contratados temporalmente. Se trata de conjugar la complejidad de las características actuales del mercado de trabajo con el intento, de evitar en lo posible, la corruptela de mantener estos contratos a tiempo parcial, al solo objeto de no caer en supuestos de descalificación de «laboral». No obstante, esta medida no ayuda a preservar la nota de laboralidad connatural a la naturaleza de este tipo social y acerca su régimen jurídico al de las sociedades de capital (Paniagua, 2013). Por lo que ha sido acertado introducir medidas legales que intenta neutralizar este riesgo, como son, las que facilitan el acceso de los trabajadores con contrato indefinido a la condición de socios posibilitando la adquisición de acciones o participaciones, si bien, quedan excluidos de esta posibilidad los trabajadores con contratos a tiempo parcial; también aquéllas medidas que allanan la conversión de acciones o participaciones sociales de la clase «laboral» a la clase «general»o viceversa o, medidas que prohíben expresamente las acciones o participaciones sin voto o con voto múltiple.

El tercer requisito exigido para la obtención de la calificación de «laboral» obliga a que la sociedad constituya una reserva especial (art. 14 de la LSLP), dado que su incumplimiento es causa de descalificación. La misma debe dotarse con el diez por ciento del beneficio líquido de cada ejercicio. La novedad introducida en este caso reside en que se limita su cuantía, al menos hasta que alcance una cifra superior al doble del capital social, y en que, se amplía el destino que puede darse a la misma. Si antes solo podía destinarse a la compensación de pérdidas en el caso de que no existieran otras reservas disponibles suficientes para ese fin. Ahora, además, puede destinarse a la adquisición de sus propias acciones o participaciones sociales, que deberán ser enajenadas a favor de los trabajadores de la sociedad con contrato por tiempo indefinido. Finalidad que ha sido demandada por un amplio sector de la doctrina que enjuiciaba muy duramente este requisito tal y como estaba recogido en la ley derogada (Sáenz, 2008 o, Fajardo, 2008 o, Paniagua, 2015). 


\subsection{El procedimiento administrativo de obtención por la sociedad de la calificación de «laboral» y su inscripción en los correspondientes Registros}

Como ya hemos avanzado, no es suficiente con cumplir con los requisitos exigidos por la LSLP antes expuestos, para que una sociedad anónima o limitada pueda utilizar en su denominación social el adjetivo de «laboral»o, acceder a las ventajas fiscales y sociales que lleva aparejada este tipo societario. Es necesario, además, que la sociedad anónima o limitada obtenga la calificación de «laboral» tras un procedimiento administrativo de concesión o reconocimiento (art. 2 LSLP).

Por su doble condición de sociedad de capital y de economía social quedan sometidas a un régimen especial de doble inscripción, en el Registro mercantil y en el Registro de sociedades laborales, obligados a coordinarse entre sí (art. 4 LSLP). Con la inscripción en el Registro mercantil, la sociedad adquiere su personalidad jurídica como cualquier otra, pero no podrá inscribirse en este Registro como «laboral» si no aporta un certificado de concesión administrativa de esa calificación.

De acuerdo con el artículo 2 de la LSLP, la competencia administrativa para calificar, controlar el cumplimiento de los requisitos exigidos en la LSLP o, en su caso, descalificar a una sociedad como «laboral», sigue residiendo bien en el Ministerio de Empleo y Seguridad Social, bien en los órganos competentes de las CCAA que tuvieran transferidas estas competencias. No difieren en gran medida las exigencias de procedimiento establecidas para la obtención de dicha calificación, esta norma sigue manteniendo la posibilidad de que la misma pueda ser solicitada durante la constitución de la sociedad o posteriormente a su constitución e, indica parte de la documentación que se debe aportar en cada caso, simplificando la documentación exigida en caso de solicitud por una sociedad preexistente, a la que habrá que añadir la documentación que se indique reglamentariamente (art. 2.2. LSLP).

Sí, introduce este artículo un par de novedades de consecuencias prácticas muy importantes. Una es, el anuncio de que se "llevaran a cabo actuaciones de armonización, colaboración, e información entre el Registro del Ministerio de Empleo y Seguridad Social, el Registro Mercantil y los Registros de las Comunidades Autónomas....” (art. 2.1, párrafo II).

La otra novedad es, que "los trámites necesarios para la calificación e inscripción de una sociedad como sociedad laboral podrán realizarse a través de medios electrónicos, informáticos y telemáticos que se habiliten al efecto.” (art. 2.3. LSLP). 
Dos importantes novedades que no cabe duda facilitaran las obligaciones procedimentales exigidas a estas sociedades. Si la primera novedad a que hemos hecho referencia la ponemos en conexión con el artículo 4 de la LSLP, referente a las actuaciones que deben seguir los Registros implicados en estos casos. El Registro del Ministerio de Empleo y Seguridad Social se convierte en piedra angular del sistema y actúa como una especie de Registro Central donde debe ser comunicado y quedar registrado todo lo referente a las sociedades laborales que llegue a los Registros mercantiles y órganos autonómicos competentes.

Quedando obligado el Registrador Mercantil a no poder inscribir una sociedad como «laboral»si no se aporta previamente el certificado que acredite que la sociedad ha sido así administrativamente calificada. Ni practicará inscripción alguna de modificación de estatutos de una sociedad laboral que afecte a su denominación, domicilio social, composición de capital social o régimen de transmisión de acciones y participaciones, sin que se aporte por la misma certificado del Registro de Sociedades Laborales en que conste que dicha modificación no afecta a la calificación de laboral. Especial referencia se hace al cambio de domicilio social (art. 4.6 LSLP), cuyo contenido queda expresamente coordinado con lo dispuesto en el artículo 20 de la Ley 20/2013 de Unidad de Mercado. ${ }^{9}$

Tras la reforma, la sociedad laboral cesa en la obligación de comunicar, periódicamente, al Registro administrativo las transmisiones o participaciones mediante certificación del libro-registro de acciones nominativas o libro de socios. Asumiendo esa obligación, en la nueva redacción del artículo 4.4 LSLP, los Registradores mercantiles que deben comunicar mediante formato electrónico, cualquier modificación estatutarias que pueda alterar la consideración de «laboral» de la sociedad. Así mismo, el juez que conozca de la impugnación de algún acuerdo social que afecte a la estructura societaria lo pondrá en conocimiento del Registro administrativo pertinente (art. 4.7. LSLP).

Ambos artículos están mejor redactados, de forma más amplia y completa. Aprovechan las posibilidades que ofrecen las nuevas tecnologías, en aras de una mejor

\footnotetext{
${ }^{9}$ Este artículo establece la eficacia en todo el territorio nacional de las actuaciones administrativas y en el punto 2 refiere que "Los organismos de evaluación, acreditación, certificación y otros similares legalmente establecidos en cualquier lugar del territorio nacional, tendrán plena capacidad para realizar sus funciones en todo el territorio nacional. Los reconocimientos o acreditaciones, calificaciones o certificaciones de una autoridad competente o de un organismo dependiente, reconocido o habilitado por ella, serán plenamente válidos a todos los efectos en todo el territorio nacional, sin que pueda exigirse la realización de ningún trámite adicional o el cumplimiento de nuevos requisitos."
} 
coordinación entre las distintas instituciones implicadas en la búsqueda de la tan deseada eficiencia, para una mejor protección y defensa del interés económico general en cumplimiento también, de la ya mencionada la Ley 20/2013 de Unidad de Mercado. ${ }^{10} \mathrm{Al}$ mismo tiempo, los artículos comentados, persiguen implícitamente el propósito de obtener un mayor y más rápido conocimiento de cualquier cuita relativa a la calificación de «laboral» de la sociedad, ya sea mediante acuerdos sociales o mediante pronunciamientos judiciales, que permita actuar en consecuencia a los órganos implicados. Para ello, delimitan mejor las obligaciones de los distintos registros e instituciones y de los medios para llevarlas a cabo. A la vez que se simplifican los procedimientos administrativos, y se ponen, también, a disposición de los usuarios éstas herramientas informáticas que facilitan a la sociedad la tramitación de dichos procedimientos, a fin de que la complejidad de los mismos no sirva de acicate para desincentivar el uso de este tipo societario.

\subsection{Modificaciones en distintos rasgos de régimen jurídico de las sociedades laborales}

La nueva ley mantiene en esencia el mismo régimen jurídico previsto en la ley derogada, no obstante, parece tomar en consideración, algunas de las críticas doctrinales realizadas a la anterior LSL y la nueva LSLP introduce mejoras en algunos aspectos sensibles de régimen jurídico, y también, ciertas novedades muy significativas, como seguidamente tendremos ocasión de exponer.

La derogada LSL disciplinaba de forma imperativa el régimen jurídico referente al capital social, a su transmisión y a los órganos sociales, que aunque abarcaban el grueso de la norma sus preceptos estaban redactados de forma farragosa y de contenido insuficiente que creaban confusión e inseguridad jurídica en su interpretación. Sin ánimo de exhaustividad, y solo a título de ejemplo, podemos referir que se discutía, sobre las posibles formas de composición de las mayorías del capital social, si solo podía formarse mediante títulos de la clase «laboral», o también, con los de clase «general»si eran propiedad de socios trabajadores por tiempo indefinido. $\mathrm{O}$, acerca del inoperante sistema voluntario de solicitud de cambio de

\footnotetext{
${ }^{10}$ Esta norma obliga a todas las Administraciones Públicas en todos sus actos y disposiciones y para todas las actividades económicas. Sin perjuicio de las competencias que en cada caso corresponden al Estado, las Comunidades Autónomas o las Entidades Locales, dotando de eficacia en todo el territorio nacional a las decisiones tomadas por la autoridad competente de origen, basadas en un criterio de confianza mutua, y se aplican principios comunes, como el principio de eficacia, en todo el territorio nacional de las actuaciones administrativas en la libre iniciativa económica, lo que implica el reconocimiento implícito de actuaciones de las autoridades competentes de otras Administraciones Públicas que simplifique la legislación existente, elimine regulaciones innecesarias, establezca procedimientos más ágiles y minimice las cargas administrativas.
} 
clase de los títulos. ${ }^{11}$ También, era objeto de crítica el tortuoso sistema de transmisión de títulos representativos del capital social o, la obligatoriedad de utilizar el sistema de representación proporcional para el nombramiento de consejeros en caso de que la sociedad organizara su órgano de administración mediante un consejo de administración, etc. Cuestiones todas ellas que han sido revisadas con mayor o menor acierto como expondremos a continuación.

\subsubsection{Modificaciones en torno al capital social, a los títulos en que queda representado y, a} sus procedimientos de transmisión previstos en la Ley

El régimen jurídico que regula al capital social y todo lo concerniente al procedimiento de transmisión de los títulos en que queda representado el capital se recoge en los artículos 5 a 12 LSLP. Sobre ellos recaen las principales especialidades del sistema que conforman un régimen propio y alejan a estas sociedades del régimen general previsto para las sociedades de capital.

El contenido de estos artículos se encaminan a implementar la finalidad perseguida por las sociedades laborales, y a tal efecto, establecen los procedimientos a seguir para que la sociedad cumpla con los requisitos tipológicos exigidos a este tipo social.

En primer lugar haremos referencia a las novedades que con distinto alcance se introducen en torno al capital social, para después, en segundo lugar, tratar las que se refieren a su transmisión.

Las sociedades laborales tendrán el capital social representado por acciones nominativas o participaciones sociales que se agruparan en torno a las de clase «laboral» y a las de clase «general». Las primeras, necesariamente serán propiedad de los socios trabajadores por tiempo indefinido (art. 5 LSLP). Varias novedades contiene lo dispuesto en este artículo.

La primera novedad, es que todos los títulos, cualquiera que sea su clase, tendrán el mismo valor nominal, conferirán los mismos derechos económicos y no podrá haber acciones

\footnotetext{
${ }^{11}$ Los socios trabajadores por tiempo indefinido deben ser propietarios de la mayoría del capital social. Estos pueden ser titulares de títulos de la clase laboral y general. La ley derogada no establecía expresamente si ambos títulos servían para conformar la mayoría exigida o solo debían tenerse en cuenta los de la clase laboral. Además dejaba a voluntad del trabajador la solicitud de conversión de una clase en otra. Lo que en ocasiones hacía incurrir en causa de descalificación.
} 
o participaciones privadas del derecho de voto (art. 5.1.LSLP). ${ }^{12}$ Como ya hemos adelantado, ésta excepción al régimen general de sociedades de capital obedece a la necesidad de evitar posibles divergencias entre la propiedad del capital y el control efectivo de la sociedad. ${ }^{13} \mathrm{La}$ práctica ha demostrado que, sobre todo, en las sociedades laborales de responsabilidad limitada, no siempre se correspondía la mayoría del capital social con el control de la sociedad como exige la propia naturaleza de la sociedad laboral. Para obviar este indeseado resultado algunas sociedades introducían estas prohibiciones en sus estatutos sociales. No obstante, es acertada su previsión legal para dejar de hacerlo depender de la autonomía de la voluntad de los socios y, asegurar así, que el deseado control de la sociedad quede en manos de los socios trabajadores con contrato por tiempo indefinido.

La segunda novedad, permite conferir al régimen jurídico de estas sociedades un importante grado de seguridad jurídica, por cuanto la LSLP admite un sistema de conversión automática de una clase a otra de los títulos en razón de que su titular sea un socio trabajador por tiempo indefinido. Así la consideración de «laboral» de un título lo hace residir en su titular, es decir, que este sea un socio trabajador por tiempo indefinido. Se despeja de esta forma la duda que antes existía sobre si podía conformarse la mayoría del capital, tanto con los títulos de la clase «laboral» como «general»si estaban en posesión de un socio trabajador por tiempo indefinido o solo podían servir para este menester los de clase «laboral». Ahora, si su titular es un socio trabajador por tiempo indefinido, sus títulos pasaran a formar parte de la clase «laboral» de forma automática, y no cabe la discusión, la mayoría del capital estará formada por títulos de la clase laboral (art. 5.2. LSLP). A "sensu contrario" si el socio ha dejado de ser un trabajador por tiempo indefinido o ha heredado títulos de la clase «laboral» estos pasarán a ser de la clase «general».

Por último, como complemento de lo anterior, se introduce también como novedad, el rediseño en el procedimiento para reconocer el cambio de clase de los títulos, de la clase «general» a la «laboral»y viceversa.

\footnotetext{
${ }^{12}$ El término clase en las sociedades laborales no se utiliza en el sentido que se utiliza en las sociedades de capital para referirse al conjunto de derechos que otorgan cada clase de acciones o participaciones independientemente de su titular. En las sociedades laborales el término hace referencia a la clase de socio y no al conjunto de derechos que otorga que, como hemos visto, por ley no puede ser distintos.

${ }^{13} \mathrm{La}$ intencionalidad buscada con esta medida fue puesta de manifiesto en el Dictamen 6/2015, de 13 de mayo del Pleno del Consejo Económico y Social.
} 
Antes, era el socio quién voluntariamente lo podía solicitar a los administradores, con la consecuente complicación para la sociedad si este no hacía uso de ese derecho. Tanto, que incluso la sociedad podía ver comprometida su calificación de «laboral» al no tener medios para conocer las transmisiones de los títulos que representan al capital social, y por ende, si la mayoría del capital social estaba detentada por los socios trabajadores por tiempo indefinido. Para obviar estos inconvenientes, el procedimiento recae, ahora, sobre los administradores sociales, quienes en caso de transmisión de acciones o participaciones que supongan un cambio de clase por razón de su propietario, sin necesidad de acuerdo de la Junta General, procederán a formalizar la modificación del artículo o artículos de los estatutos a los que ello afecte y a su inscripción en los registros laboral y mercantil, así como, a reflejar las variaciones de capital en la memoria anual de las sociedades laborales (art. 5.3.4. LSLP).

Por tanto, el paso de una clase a otra se hará de forma automática y el sistema procedimental se desplaza del socio hacia los administradores que, serán así, los garantes de que se cumplan las exigencias porcentuales exigidas en el artículo 1 LSLP. Y la Junta General conocerá de los cambios a través de la memoria anual o de la consulta de los asientos registrales.

En cuanto al sistema de transmisión de las acciones o participaciones sociales en las que se divide el capital social queda organizado a lo largo de los artículos 6 a 12 LSLP. No es extraño el número de preceptos dedicados a su regulación en comparación a los que dedica la LSLP a otros rasgos configuradores del sistema de las sociedades laborales. Dado que la transmisión de títulos es un instrumento idóneo para preservar el carácter social de este tipo de sociedades facilitando el acceso de los trabajadores por tiempo indefinido a la condición de socio, pilar fundamental de su especial naturaleza jurídica.

El régimen derogado preveía un sistema de comunicación individual y jerarquizado en el ejercicio del derecho de adquisición preferente tanto, de los títulos de la clase «laboral» como, de la clase «general», para una transmisión «inter vivos» o «mortis causa», ya fuera voluntaria o forzosa, que resultó ser demasiado farragosa en su redacción y muy confusa en su comprensión (Andreu, 2014 o Santos, 2002 y 2007).

El nuevo régimen jurídico de transmisión de los títulos en que se representa el capital social queda diseñado como un sistema más ágil, se simplifica el sistema de adquisición preferente y se reducen los plazos y el colectivo con derechos de preferencia ya que se 
suprime el derecho que ostentaban los trabajadores de duración determinada" (Ex. Mot. III, párr. 6).

Es cierto que la técnica legislativa ha sido mejorada, tanto en la forma como en el fondo. La mejor redacción de los preceptos permite una mejor comprensión de sus disposiciones y reduce las cuestiones que pueden prestarse a interpretación.

El régimen jurídico de transmisión de acciones o participaciones sociales está diseñado en la nueva norma con un mayor margen a la autonomía de la voluntad que el sistema derogado que era mucho más imperativo.

Se mantiene que los socios puedan en los estatutos sociales establecer el procedimiento de transmisión que acuerden entre todos, con la única limitación legal de que será nula la cláusula estatutaria que prohíba la transmisión voluntaria de las acciones o participaciones sociales por actos «inter vivos» si no reconocen al socio el derecho de separarse de la sociedad en cualquier momento. Esta cláusula estatutaria exige el consentimiento de todos los socios (art. 8.1. LSLP). No obstante, esta prohibición queda atemperada durante un periodo de cinco años desde que se constituya la sociedad. También se prevé esta moratoria en caso de ampliación de capital a contar, dicho plazo de cinco años, desde que se otorga la escritura pública de su ejecución (art. 8.2 LSLP). Estas medidas son comúnmente aceptadas para los tipos de sociedades cerradas, dado que no se puede impedir que el socio se vaya de la sociedad, a la vez que se intenta preservar al proyecto empresarial de movimientos continuos de capital durante un periodo de tiempo prudencial hasta darle tiempo a que el mismo se estabilice. En definitiva, estas medidas protegen el derecho del socio de abandonar la organización societaria sin poner en peligro el proyecto empresarial.

Si nada dicen los estatutos sociales, la LSLP recoge el procedimiento de transmisión de títulos, voluntaria o forzosa, «inter vivos» $\mathrm{y}$ «mortis causa» que deben seguir las sociedades laborales.

El procedimiento de transmisión voluntario «inter vivos» gira en torno al derecho de adquisición preferente trazado en el artículo 6 de la LSLP con varias novedades que permiten una mayor agilidad del sistema.

La primera novedad es que se unifica el procedimiento de transmisión para ambas clases de títulos, «laboral»y «general». El artículo 6 no hace referencia a ningún título en 
particular. ${ }^{14}$ Articula el sistema en torno a dos situaciones, será libre la transmisión de títulos entre los trabajadores por tiempo indefinido sean socios o no (art. 6.1 LSLP). Y, los demás supuestos (art. 6.2. LSLP).

La primera posibilidad o situación viene a despejar la duda en torno a si era necesario que concurrieran en el adquirente de títulos de la clase «laboral» la doble condición de socio y trabajador por tiempo indefinido. Ahora, la norma recoge expresamente que pueden transmitirse libremente los títulos de cualquier clase que sean, al no hacer distingos, tanto a socios trabajadores como trabajadores por tiempo indefinido no socios.

En este primer supuesto, el procedimiento de transmisión que debe seguir el socio transmitente (art. 6.1II LSLP), no se desvía del procedimiento previsto para las sociedades de capital no cotizadas. Con mayor razón en las sociedades laborales sometidas a límites porcentuales en la posesión del capital social de los socios y para la conformación de las mayorías con las que obtener y mantener la condición de «laboral». De ahí, que "Toda transmisión de acciones o participaciones, cualquiera que sea su clase y circunstancias, quedará sometida al consentimiento de la sociedad si con la misma se pueden superar los límites previstos en el artículo 1 de esta ley.” ( art. 6.3 LSLP), verdadero caballo de batalla de este tipo societario dado que su transgresión le hace perder su calificación de «laboral» como venimos afirmando.

También se introducen importantes novedades en el procedimiento previsto en la segunda situación o posibilidad antes dicha, los demás supuestos (art. 6.2 LSLP). Aquí, se reducen los plazos y simplifican los trámites.

La norma introduce una reducción en los plazos, si estos se cumplen, en no más de 40 días puede resolverse la cuestión, ello permite mayor rapidez en la resolución de la transmisión. ${ }^{15}$ No obstante, la mayor novedad introducida permite dotar al procedimiento de una gran agilidad, y es, que los administradores pueden comunicar de forma simultánea a todos los interesados la posibilidad que tienen de ejercer su derecho de adquisición preferente. Abandonando así, el farragoso sistema anterior de comunicación jerarquizada a medida que iban renunciando a ese derecho los distintos interesados.

\footnotetext{
${ }^{14}$ El ex artículo 7 LSL se refería constantemente a los títulos de la clase «laboral» y en el último apartado 8 de éste artículo 7, hacía referencia expresa a los títulos de la clase «general».

${ }^{15}$ Se reducen una media de 10 días, la reducción más llamativa se produce cuando el socio no ha procedido a transmitir las acciones o participaciones y debe iniciar de nuevo los trámites, que pasa de cuatro meses a dos meses.
} 
Otra novedad, pero esta vez sopesada negativamente es que se limita el ejercicio del derecho de adquisición preferente: a los trabajadores por tiempo indefinido no socios, a los socios trabajadores y, a los socios inversores o de clase general. Quedan excluidos los trabajadores con contrato temporal (Paniagua, 2015). Si bien, a través de los estatutos sociales se puede ampliar el circulo de destinatarios de ese derecho. En este caso se ha optado legalmente por reforzar el régimen capitalista de esta estructura societaria, antes que potenciar la naturaleza social de estas sociedades, apostando porque estos trabajadores con contratos laborales a tiempo parcial pudieran acceder a los medios de producción. Una muestra más del difícil equilibrio que a veces supone para las sociedades laborales mantener su doble condición de sociedades de capital pero de naturaleza social.

Estos grupos de destinatarios de los títulos que se transmiten, quedan dispuestos en orden de prioridad, primero podrán adquirir los trabajadores por tiempo indefinido no socios, para facilitar el principio democrático en que se asientan estas sociedades y promover que el mayor número posible de trabajadores por tiempo indefinido puedan acceder a la categoría de socios. En segundo lugar, los socios trabajadores por tiempo indefinido, en tercer lugar los socios no trabajadores, y por último, la sociedad (art. 6.2.II LSLP). Dos novedades a destacar en este apartado del precepto, de una parte, se modifica el sistema de distribución de títulos en el caso de concurrir varias personas en el ejercicio de este derecho de adquisición preferente, que pasa de un reparto por igual entre todos los aspirantes independientemente de su participación en el capital, a un reparto en proporción inversa a la participación que cada uno de los solicitantes tuviera en el capital social. Más acorde con los postulados de la economía social. Si no se presentasen ofertas de compra en el plazo previsto el titular de los títulos podrá transmitirlos libremente.

De otra parte, son también de nuevo cuño, las condiciones exigidas por el artículo 12 de la LSLP para el caso de que la sociedad adquiera sus propias acciones o participaciones. La sociedad laboral solo podrá adquirir sus títulos con cargo a beneficios, a la reserva especial o a otras reservas disponibles. No podrá, por tanto, endeudarse para este menester. Además, la adquisición está sometida a finalidad, puesto que la sociedad queda obligada por la norma a enajenarlas a favor de sus trabajadores por tiempo indefinido en un plazo máximo de tres años, en caso contrario debe proceder a su amortización, salvo que en su conjunto las acciones o participaciones no excedan del 20 por ciento del capital social. 
La sociedad actúa como un intermediario que adquiere las acciones o participaciones por tiempo limitado, tres años, ${ }^{16}$ a fin de permitir que los trabajadores por tiempo indefinido que desean adquirir la condición de socio estén en disposición de obtener los recursos económicos necesarios, antes de que sean adquiridas por terceros ajenos al círculo de trabajadores (Andreu, 2010).

En cualquiera de las anteriores circunstancias, la transmisión queda sometida al consentimiento de la sociedad, como forma de controlar que no se superan límites porcentuales previstos en el artículo 1 para acceder a la condición de «laboral» por parte de la sociedad (art. 6.3. LSLP).

Otra novedad de especial calado introducida por la nueva norma en el régimen jurídico de las sociedades laborales, y que ya fue muy reclamado por la doctrina. Es, que ahora, la sociedad laboral puede auxiliar económicamente a sus trabajadores no socios para facilitar que puedan alcanzar dicha condición, permitiendo a la sociedad "anticipar fondos, conceder créditos o préstamos, prestar garantías o facilitar asistencia financiera para la adquisición de sus propias acciones o participaciones. Remitiendo en todo lo demás al régimen general aplicable a las acciones o participaciones previsto en la Ley de Sociedades de Capital (art. 12.5 LSLP) (Barrero, 2015).

Se supera para estas sociedades la natural reticencia por parte de la doctrina, reflejada también en la legislación societaria, que con carácter general impide que la sociedad preste ayuda financiera a sus socios para adquirir sus propias acciones o participaciones, reclamándose incluso la nulidad del negocio jurídico realizado con el importe de la ayuda. No obstante, ya hay una importante corriente doctrinal a favor de que se revise la rigidez de la prohibición de asistencia financiera para la adquisición de sus propias acciones o participaciones cuando no perjudiquen los intereses en juego (Vargas, 2015) y que ha tenido reflejo en la propia Ley que la admite para los trabajadores de la sociedad con contrato por tiempo indefinido que no sean socios (art. 12.4 LSLP).

Para soslayar las posibles situaciones de injusticia que pueden darse entre los distintos socios y la inseguridad jurídica que ello puede acarrear, la sociedad puede adoptar medidas de compensación (Sáenz, 2008).

\footnotetext{
${ }^{16}$ Este plazo era el previsto en el PLSL, siendo considerado demasiado amplio por el Dictamen 62015 emitido por el Consejo Económico y Social. De mayo de 2015.
}

REVESCO No 123 - Primer Cuatrimestre 2017 - ISSN: 1885-8031 - www.ucm.es/info/revesco 
Aunque con menor transcendencia que lo anterior, debemos detenernos también, en la transmisión forzosa «inter vivos» de acciones y participaciones sociales, regulada en el artículo 9 de la LSLP, que recoge tres supuestos de transmisión forzosa de los títulos.

El primer supuesto, se refiere a la extinción de la relación laboral, ya previsto en el régimen derogado, la única diferencia es que ahora, el nuevo régimen establece un plazo máximo de un mes para que el socio que ha perdido la condición de trabajador, bien por extinción del contrato de trabajo, bien por jubilación, ponga sus títulos a disposición de los posibles interesados que forman los grupos previstos en el artículo 6 LSLP ya mencionado, salvo que otra cosa dispongan los estatutos para estos casos (art. 9.1.2. LSLP). Este precepto prevé las dos posibles situaciones en que puede derivar este supuesto de hecho: una, que no haya ofertas de adquisición y, en ese caso, los títulos pasarían a la clase «general» siguiendo el procedimiento previsto en el artículo 5 de la LSLP; otra, que habiendo interesados en adquirir dichos títulos, el socio que ya hubiera sido requerido notarialmente para la venta de sus títulos no proceda en el plazo de un mes a formalizar la venta, en este caso la ley admite que dichos títulos puedan ser otorgados por el órgano de administración.

El segundo y tercer supuesto previstos en el artículo 9 de la LSLP se refiere al embargo de las acciones y participaciones de la sociedad o, a la ejecución de la prenda constituida sobre las mismas (art. 9.3 LSLP). Este precepto remite expresamente al régimen general regulado en el art. 109 de la Ley de sociedades de capital. Solo establece dos particularidades ajenas a ese régimen general. Una, que las notificaciones se hagan también a los trabajadores no socios con contrato indefinido, y dos, que el derecho de subrogación previsto se ejercite en el orden previsto en el artículo 6 de la LSLP. Dichas particularidades se anudan al rasgo de «laboral» de la sociedad, verdadero nudo gordiano de las sociedades laborales.

Por último, el régimen de transmisión «mortis causa» de las acciones o participaciones sociales no sufre alteración significativa. Tan solo, reduce el plazo a tres meses para ejercitar el derecho de adquisición preferente desde la comunicación a la sociedad de la adquisición hereditaria (art. 10 LSLP). Y, se condiciona la transmisión «mortis causa» al consentimiento de la sociedad, única valedora del cumplimiento de los porcentajes a que queda sometida la misma en el artículo 1 LSLP. Con el fin de evitar el riesgo que suponía los movimientos de 
capital sin que hubiera ningún instrumento de control, lo que ponía en peligro la formación de las mayorías como fue anunciado por la doctrina en su día. ${ }^{17}$

\subsubsection{Modificaciones en torno a los órganos sociales}

La norma sigue dedicando un solo artículo a establecer el régimen jurídico del órgano de administración (art. 13 LSLP). Nada dice específicamente sobre la junta general de socios, por lo que ésta se regirá sin excepción por el régimen general de anónimas o limitadas, además de las funciones que expresamente le atribuye esta ley especial (Boquera, 2002).

En cuanto al órgano de administración el contenido del artículo 13 es especialmente novedoso respecto del derogado. Este artículo mas que establecer las diferencias de régimen jurídico respecto de los órganos de administración, enuncia dos cuestiones, una hace referencia expresa al sistema de representación proporcional previsto en la LSC y, admite que pueda ser utilizado por los titulares de las acciones o participaciones de la clase «general» en caso de que la administración de la sociedad se organice mediante un consejo de administración (art. 13.2 LSP) (Lara, 1998 o Embid, 2015). Sigue sin entenderse porqué se mantiene esta posibilidad, prevista más bien para grandes sociedades, aunque ahora queda matizada su anterior redacción en dos cuestiones, se hace expresa referencia a que sólo los titulares de las acciones o participaciones de la clase «general» podrán seguir este procedimiento, imaginamos que para proteger así los derechos de la minoría, aunque se podría haber optado por otra forma menos costosa. Y pierde la obligatoriedad a que quedaba sometida en la norma derogada, al usarse ahora el verbo "podrá", lo que deja a la autonomía de la voluntad de los titulares de los títulos de la clase «general» su utilización o no. Al perder el carácter imperativo, puede matizarse la utilización de este sistema en los estatutos sociales.

No obstante, sigue siendo una excepción a la LSC cuyo régimen general diseñado para las sociedades de responsabilidad limitada no lo prevé. Esta excepción nunca fue entendida por la doctrina que consideraba que los derechos de la minoría podían defenderse por otras vías. Incluso, algunos autores ven una "extralimitación del legislador", ya que esta fórmula de elección aparece circunscrita en nuestro derecho de sociedades a la sociedad anónima y no se

\footnotetext{
17 Entre las causas que se aportaban para solicitar la reforma de la Ley de Sociedades Laborales, era precisamente, la dificultad que tenía la sociedad de controlar los movimientos de capital, dando lugar incluso a incurrir en causa de descalificación.
} 
alcanza a entender la razón de llevar la indicada extensión institucional a las sociedades limitadas laborales (Embid, 2015).

No encontramos ninguna referencia que lo justifique ni en la exposición de motivos de la LSLP, ni en su parte dispositiva.

Mayor preocupación muestra el precepto por acomodar implícitamente el comportamiento de los administradores a lo dispuesto en la Ley 31/ 2014, de 3 de diciembre, por la que se modifica la Ley de Sociedades de Capital para la mejora del gobierno corporativo. De obligado cumplimiento para todas las sociedades, también las laborales. Y en el marco de esta norma obliga a actuar a los administradores, de una parte, promoviendo aquello que es consustancial a la propia naturaleza de este tipo de sociedades, y por tanto, la política social tiene que ir encaminada a su consecución aunque no estuviera expresamente previsto en la norma (art. 13.3 LSLP), y de otra, deben tener un comportamiento socialmente responsable (art. 13.4. LSLP). Se echa en falta mecanismos concretos que obliguen a los administradores a impulsar dichas medidas, por lo que parece más un deseo del legislador que un mandato.

\section{PÉRDIDA DE LA CALIFICACIÓN DE «LABORAL» POR LA SOCIEDAD}

Las causas de pérdida de la calificación de «laboral» por parte de la sociedad están previstas en el artículo 15 de la LSLP que hay que ponerlo en relación con el artículo 1.3 LSLP, que establece los plazos y los requisitos para evitar la descalificación. No ha sido afortunada la redacción de este artículo, porque, si bien, están claras las causas de pérdida de la sociedad de la calificación de «laboral» y sus consecuencias, no ocurre lo mismo con los plazos y procedimientos a seguir para llegar a la descalificación administrativa donde se utiliza una técnica de remisiones poco clara.

Las causas siguen residiendo en el incumplimiento de los requisitos legales a que se anuda la calificación de «laboral» del artículo 1 y 14 LSLP, a las que se le añade una nueva causa, que es la posibilidad admitida legalmente de decidir democráticamente en junta general mediante acuerdo solicitar la pérdida de la calificación de «laboral» (art. 15. 4. LSLP).

La consecuencia de la descalificación es económica, puesto que conlleva la pérdida y el reintegro de los beneficios y ayudas públicas, adquiridos como resultado de su condición de sociedad laboral desde el momento en que la sociedad incurre en causa de descalificación (art. 
15.5 LSLP). Su análogo derogado solo contemplaba la pérdida de beneficios tributarios cuando la sociedad era descalificada antes de los cinco años desde que se había constituido o transformado la sociedad para aplicar esta sanción. Sin hacer ninguna referencia expresa a qué consecuencia tenía la pérdida de la calificación de «laboral» transcurridos esos cinco años. ${ }^{18}$ Por tanto, es de agradecer que ahora quede especificado con mayor claridad cuál es la consecuencia y desde cuando se aplica la misma.

La norma sigue admitiendo la posibilidad de enmendar la situación de descalificación en que esté inmersa la sociedad, siempre que corrija dicha causa (art. 15.2 LSLP). Para ello remite a lo dispuesto en el artículo 1.3 de la LSLP que obliga a la sociedad a comunicar al Registro de sociedades laborales, en el plazo de un mes desde que se produce la casusa, qué limites superó y en qué circunstancias se originó dicha situación. Aunque, expresamente nada dice el artículo 15 que estamos comentando, entendemos que también por remisión al artículo 1 de la LSLP, la sociedad tendrá un plazo de doce meses para acomodar de nuevo su situación a la legislación vigente, pudiendo el Registro de sociedades laborales conceder dos prórrogas por un plazo máximo de doce meses cada una, siempre que se acredite en cada solicitud de prórroga que se ha avanzado en el proceso de adaptación a los límites previstos (art. 1.2,c. II LSLP). Nada se dice, ni en este apartado, ni en otros, de qué circunstancias debe tomar en consideración el Registrador para autorizar las prórrogas solicitadas y quedará a su discrecionalidad si lo aportado por la sociedad supone un avance en ese proceso de adaptación.

Es posible que este procedimiento quede concretado a través de las normas de desarrollo de esta ley en cumplimiento de lo dispuesto en el apartado 3 de este artículo 15.

\section{RECAPITULACIÓN FINAL}

La nueva ley no termina con la indefinición legal que recae sobre la naturaleza jurídica de estas sociedades. Tampoco lo pretendía. La LSLP sigue considerando a las sociedades laborales como sociedades de capital que una vez obtenida la calificación de «laboral» modifican su naturaleza jurídica pudiendo alcanzar la consideración de sociedad de economía social. Sin que ello haya sido suficiente razón para dotarlas legalmente de un régimen jurídico específico que regule con seguridad las singularidades de la figura. Nada se ha avanzado en este terreno.

${ }^{18}$ Artículo 16.4 de la LSL

REVESCO No 123 - Primer Cuatrimestre 2017 - ISSN: 1885-8031 - www.ucm.es/info/revesco 
El nuevo texto legal se desenvuelve en el mismo contexto que lo hacía la LSL derogada, cuyo resultado es un régimen jurídico híbrido, basado en la técnica de la remisión con carácter general a la LSC, que no termina de dotar a estas figuras de autonomía normativa, pero que tampoco, admiten una transposición automática de muchas de sus reglas que rigen a las sociedades de capital, debido a la nota de «laboralidad» que está en la base de la especificidad de la figura y que las aleja de las sociedades de capital.

Al no contener esta norma un modelo regulatorio completo de este tipo societario, la valoración de la reforma hay que ceñirla a lo propuesto por la propia LSLP, según decíamos, ésta pretende modernizar su estructura jurídica, a la vez, que reforzar el perfil social que se le demanda. No obstante, para conseguir esta finalidad, la ley solo ha introducido modificaciones de escaso calado en el régimen jurídico de las sociedades laborales, lo que permite afirmar que la reforma se ha limitado, principalmente, a corregir las disfunciones observadas en la aplicación de la ley derogada.

En este contexto, hay que valorar positivamente, que sus preceptos estén redactados de forma más clara y sus contenidos estén mejor reubicados, lo que permite una mejor comprensión de lo regulado y deje menos espacio a la interpretación de los mismos, aunque ello no pase de ser unos meros ajustes de puesta al día que necesitaba la ley derogada.

También es positivo, que la LSLP establezca un régimen jurídico menos imperativo que el derogado admitiendo un mayor margen a la autonomía de la voluntad de los socios en la configuración de algunos aspectos de su régimen jurídico; que introduzca sistemas informáticos para agilizar y facilitar los procedimientos administrativos y reduzca los plazos previstos en el cumplimiento de las obligaciones impuestas a la sociedad; que ordene que se coordinen las instituciones públicas con competencias en sociedades laborales para evitar así disputas en razón de sus competencias legislativas que no llevan más que a desincentivar el uso de este tipo societario.

En cuanto al régimen jurídico propiamente dicho, la ley está trufada de pequeñas novedades introducidas en su regulación de las que ya hemos dejado constancia en el grueso del trabajo, si bien, merecen una mención especial las encaminadas a conseguir: que el control de la sociedad quede en manos de los socios trabajadores con contrato indefinido; una mejor sistematización en el procedimiento de transmisión de los títulos que representan el capital social, verdadero núcleo duro de la reforma, así como, admitir la posibilidad de que la 
sociedad pueda ayudar financieramente a sus trabajadores para facilitar que puedan alcanzar la condición de socios, piedra angular de este tipo societario.

Por otro lado, la norma una veces introduce y otras mantiene medidas cuya necesidad no queda suficientemente justificada, como, por ejemplo, la posibilidad de que dos socios puedan constituir una sociedad laboral o, por qué se excluyen a los trabajadores no indefinidos de la oportunidad de ser propietarios de los medios de producción o, por qué se sigue manteniendo el sistema de representación proporcional para el nombramiento de consejeros, etc.

Así que a la cuestión planteada al inicio de este artículo sobre si la nueva ley que regula a esta figura organizativa era el instrumento idóneo para alcanzar los fines propuestos por la misma. Podemos contestar, que si bien mejora su estructura jurídica con una puesta al día de su régimen jurídico, no parece que las medidas introducidas sean suficientes para asegurar los fines propuestos y hacer de estas sociedades una figura organizativa suficientemente atractiva para los emprendedores.

\section{BIBLIOGRAFÍA}

ANDREU MARTÍ, M DEL M. (2010) Luces y sombras de la reforma de la ley de sociedades laborales. CIRIEC-España: Revista jurídica de economía social y cooperativa, $\mathrm{N}^{\mathrm{o}} 21$, pp. 119-144.

ANDREU MARTÍ, M DEL M. (2014) Transmisiones de acciones y participaciones sociales en la reforma propuesta de la ley de sociedades laborales. CIRIEC-España: Revista jurídica de economía social y cooperativa, $\mathrm{N}^{\circ} 25$, pp. 313-342.

BARRERO RODRÍGUEZ, E. (2015) Consideraciones sobre la reforma del régimen legal de las sociedades laborales. Revista de Derecho de Sociedades, № 45, pp. 246-287.

BATLLE SALES, G. (1996) Notas sobre la sociedad anónima laboral: ventajas e inconvenientes para su adaptación a las pymes. En: Estudios jurídicos en homenaje al PROFESOR AURELIO MENÉNDEZ II. Madrid: Civitas, pp.1.52-1536

BOQUERA MATARREDONDA, J. (2002) El órgano de administración en las sociedades laborales. CIRIEC- España: Revista jurídica de economía social y cooperativa, № 13, pp. 111-124. 
CANO LÓPEZ, A. (1997) Reflexiones acerca de un «nuevo» instrumento societario: la Ley 4/1997, de 24 de marzo de sociedades laborales. Revista de derecho de Sociedades, $\mathrm{N}^{\mathrm{o}} 8$, pp. 194-213.

CANO LÓPEZ, A. (2002) El fenómeno de las uniones de empresas en el ámbito de la economía social: los grupos de sociedades laborales. En Derecho de Sociedades, libro homenaje al PROFESOR FERNANDO SÁNCHEZ CALERO, vol. V, Mc Graw Hill Interamericana de España, pp. 5229-5280.

CANO LÓPEZ, A. (2008) Algunas reflexiones tópicas al hilo de una singular y necesaria propuesta de reforma. CIRIEC- España: Revista jurídica de economía social y cooperativa. $\mathrm{N}^{\circ} 19$, pp. 1-13. Disponible en

http://www.ciriec-evistajuridica.es/index.php?id_pagina=8\&idRevista=21.

CAVAS MARTÍNEZ, F. Y SELMA PENALVA, A. (2011) El estatuto jurídico-profesional de los trabajadores en la proyectada reforma de las sociedades laborales. CIRIEC-España: Revista jurídica de economía social y cooperativa, $\mathrm{N}^{\mathrm{o}} 22$, pp.181-215.

DE LUCAS Y CADENAS, J. (1996) Las sociedades anónimas laborales. En Comunidad de Bienes, Cooperativas y otras formas de empresas II, Madrid: Colegio Notarial, pp. 1383

EMBID IRUJO, J.M. (2015) La reforma en curso de las sociedades laborales. http://www.commenda.es/ de 04/mayo/2015.

Disponible en http://www.commenda.es/rincon-de-commenda/page/6/

EMBID IRUJO, J.M (2015) Más temas para la reflexión en el anteproyecto de la ley de sociedades laborales, http://www.commenda.es, 12 de mayo 2015.

FAJARDO GARCÍA, G (2008) Aspectos societarios de la reforma de la Ley de Sociedades Laborales, CIRIEC-España: Revista jurídica de economía social y cooperativa $\mathrm{N}^{\circ}$ 19, pp. 1-18. Disponible en http://www.ciriec-revistajuridica.es/index.php?id_pagina=8\&idRevista=21.

GARCÍA RUIZ, E. (2013) El régimen legal de las sociedades laborales sometidos a revisión.

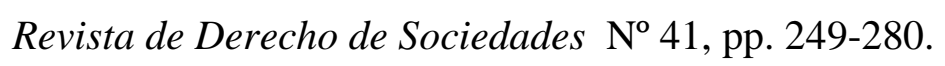

LARA GONZÁLEZ, R. (1998) La organización administrativa de las sociedades laborales y el derecho de representación proporcional. Revista de Derecho Mercantil, No 228, pp. 679- 694.

LEJARRIAGA PÉREZ DE LAS VACAS, G. Y MARTÍN LÓPEZ, S. (2013) La sociedad laboral: una forma de hacer empresa con historia. En LEJARRIAGA PÉREZ DE LAS VACAS, G.; MARTÍN LÓPEZ, S.; MUÑOZ GARCÍA, A. 40 años de historia de las 
empresas de participación. Escuela de Estudios Cooperativos de la Universidad Complutense de Madrid, edit. Verbum, pp. 305-339.

OLAVARRÍA IGLESIAS, J. (2008) Algunos aspectos societarios de la propuesta de reforma de la ley de sociedades laborales presentada por CONFESAL. CIRIEC-España: Revista jurídica de economía social y cooperativa, núm. 19, pp. 1-5. Disponible en http://www.ciriec-revistajuridica.es/index.php?id_pagina=8\&idRevista=21.

PANIAGUA ZURERA, M. (2005) La sociedad cooperativa. Las sociedades mutuas y las entidades mutuales. Las sociedades laborales. Las sociedades de garantía recíproca. En OLIVENCIA, M,; FERNÁNDEZ-NÓVOA,C.; JIMÉNEZ DE PARGA,R. Las Sociedad Cooperativa, Las sociedades Mutuas de Seguros y las Mutualidades de previsión social. Vo. 1 (DM12), Madrid-Barcelona, Marcial Pons, pp. 427.

PANIAGUA ZURERA, M. (2013) La sociedad-empresa cooperativa en la evolución de los modelos ius cooperativos de España. Revista de Derecho de Sociedades № 40, pp. 159205.

PANIAGUA ZURERA, M. (2013) Notas críticas a la Ley 14/2011, de 23 de diciembre, de sociedades cooperativas andaluzas, CIRIEC- España: Revista jurídica de economía social y cooperativa, $\mathrm{N}^{\mathrm{o}} 24, \mathrm{pp} .53-116$.

PANIAGUA ZURERA, M. (2015) La singularidad tipológica de la sociedad laboral y su legislación adecuada. (A propósito de la Proposición de Ley de sociedades laborales de Confesal y de la aplicación judicial de la Ley 4/1997, de sociedades laborales). Revista de Derecho de Sociedades, $N^{\circ}$ 44, pp. 171-232.

PANIAGUA ZURERA, M. (2015) Las sociedades laborales en el Anteproyecto de Ley de Código Mercantil. En ILLESCAS ROJAS, C.; ILLESCAS ROJAS, E.; ILLESCAS ROJAS, A. Estudios sobre el futuro Código Mercantil. Libro homenaje al profesor RAFAEL ILLESCAS ORTIZ. Universidad Carlos III de Madrid, pp. 726-744. Disponible en

http://earchivo.uc3m.es/bitstream/handle/10016/21060/sociedadeslaborales_paniagua_RIO_2015. pdf? sequence $=1$.

PORTELLANO DÍEZ, P. y MERCADER UGUINA, J.R. (1997) La sociedad laboral: sencillamente una sociedad especial (A propósito de la Ley 4/1997, de 24 de marzo de sociedades laborales) Revista de Relaciones Laborales N $^{\circ}$ 12, pp.1155-1199. 
SÁENZ GARCÍA DE ALBIZU, J.C. (2008) Propuesta de reforma de Ley de 1997 de sociedades laborales.- CONFESAL- problemas societarios. CIRIEC-España: Revista jurídica de economía social y cooperativa, núm. 19, pp.1-9. Disponible en http://www.ciriec-revistajuridica.es/index.php?id_pagina=8\&idrevista=21.

SANTOS MARTÍNEZ, V. (2002) Sociedades laborales: implantación y renovación de una peculiar figura societaria. En Derecho de Sociedades. Libro Homenaje al profesor Fernando Sánchez Calero, vol. IV, edit. McGraw-Hill Interamericana de España, pp. 4379-4466.

SANTOS MARTÍNEZ, V (2007) Transmisiones de las acciones y participaciones sociales laborales. En Estudio de Derecho de Sociedades y Derecho Concursal. Libro homenaje al profesor RAFAEL GARCÍA VILLAVERDE. Tomo II, Marcial Pons, Consejo del Notariado de España, Caja de Ahorros y Monte de Piedad, pp. 1269-1308.

URÍA, R, MENÉNDEZ, A. y VÉRGEZ, M. (2006) Sociedades de garantía recíproca y sociedades laborales. En URÍA y MENÉNDEZ Curso de Derecho Mercantil I, pp. 14471465.

VARGAS VASSEROT, C. (2006) La actividad Cooperativizada y las relaciones de la cooperativa con sus socios y terceros. Monografía, № 27, Revista de Derecho de Sociedades, p. 257.

VARGAS VASSEROT, C. (2015) Los efectos jurídicos de la controversia de la prohibición de asistencia financiera para la adquisición de acciones propias. En ILLESCAS ROJAS, C.; ILLESCAS ROJAS, E.; ILLESCAS ROJAS, A. Estudios sobre el futuro Código de Derecho Mercantil. Libro homenaje al profesor Rafael Illescas Ortiz. Universidad Carlos III de Madrid, pp. 967-988. 